\title{
Laparoscopic resection of hepatocellular carcinoma in patients with and without cirrhosis: the Brisbane experience
}

\author{
Daniel J. Kilburn ${ }^{1,3}$, Universe Leung1, David J. Cavallucci ${ }^{1,3}$, Cassandra Jeavons ${ }^{1}$, Mehan Siriwardhane ${ }^{1,2}$, Richard \\ Bryant $^{1}$, Thomas R. O'Rourke ${ }^{2}$, Shinn Yeung ${ }^{2}$, Nicholas A. O'Rourke ${ }^{1,3}$
}

\author{
'Hepatopancreatobiliary Unit, Department of Surgery, Royal Brisbane and Women's Hospital, Brisbane, Queensland 4029, Australia. \\ ${ }^{2}$ Hepatopancreatobiliary Unit, Department of Surgery, Princess Alexandra Hospital, Brisbane, Queensland 4102, Australia. \\ ${ }^{3}$ School of Medicine, The University of Queensland, Brisbane, Queensland 4072, Australia.
}

Correspondence to: Dr. Nicholas A. O’Rourke, Wesley Medical Centre Suite 47, 40 Chasely Street, Auchenflower, Brisbane, Queensland 4066, Australia. E-mail: orourke.nick@gmail.com

How to cite this article: Kilburn DJ, Leung U, Cavallucci DJ, Jeavons C, Siriwardhane M, Bryant R, O'Rourke TR, Yeung S, O'Rourke NA. Laparoscopic resection of hepatocellular carcinoma in patients with and without cirrhosis: the Brisbane experience. Hepatoma Res 2016;2:264-70.

Dr. Nicholas A. O'Rourke (Right) and Dr. Daniel J. Kilburn (Left) are co-authors of this paper. Dr. O'Rourke
is the Chairman of General Surgery and the Chief of HPB at the Royal Brisbane Hospital (RBH), Brisbane,
Queensland, Australia. He is an immediate past President of ANZHPBA and current Secretary-General
of the International Laparoscopic Liver Society (ILLS). Dr. Kilburn is a surgical resident at the RBH with a
keen interest in laparoscopic HPB surgery.

Article history:

Received: 08-07-2016

Accepted: 09-08-2016

Published: 30-09-2016

Key words:

Hepatocellular carcinoma,

hepatoma,

hepatectomy,

laparoscopic surgery,

liver cirrhosis

\begin{abstract}
Aim: Laparoscopic liver resection for hepatocellular carcinoma (HCC) is increasingly common around the world. There may be significant advantages over open resections. However, due to technical difficulties, they are performed in few centers with expertise in liver and advanced laparoscopic surgery. In this study the authors summarize the experience to date. Methods: A retrospective analysis of consecutive patients undergoing laparoscopic liver resection for HCC in 2 tertiary academic hepatobiliary units in Brisbane, Australia, between 1999 and 2015 was performed. Operative characteristics, perioperative morbidity, and pathological data were described. Patients with and without cirrhosis were analyzed and compared. Results: Fifty-two patients underwent resection of 79 HCCs. Sixty-five percent of patients had cirrhosis. Fourteen percent of patients underwent a major hepatectomy. There was a trend towards more parenchyma-sparing resections for cirrhotic patients. Blood loss was higher in cirrhotics. Conversion to an open procedure occurred in $9 \%$. There was one 90 -day mortality due to liver failure $(1.9 \%)$, and 7 patients $(13 \%)$ experienced a complication. R0 resection was achieved in $92 \%$. Overall survival at 1, 3, and 5 years was $88 \%, 81 \%$, and $61 \%$, respectively. Conclusion: Laparoscopic liver resection for HCC, particularly in cirrhotic patients, is technically challenging. It can be performed with acceptable morbidity and adequate surgical margins.
\end{abstract}




\section{INTRODUCTION}

Hepatocellular carcinoma (HCC) is the fifth most common cause of cancer and the third most common cause of cancer-related death worldwide. Furthermore, it is the leading cause of death for patients with cirrhosis. ${ }^{[1,2]}$ In North America and Europe, the incidence of $\mathrm{HCC}$ has been rising, likely due to changing risk factors for cirrhosis, including hepatitis $\mathrm{C}$ infection in baby-boomers, alcohol use, obesity, and non-alcoholic fatty liver disease. ${ }^{[3,4]}$ At presentation, only $10-15 \%$ of patients are candidates for surgical resection. Other treatment options include liver transplantation, ablation, transcatheter artrial chemoembolisation, and systemic chemotherapy. Liver resection, more commonly reported as an open procedure, is a well-established, potentially curative treatment for patients with HCC, and is the procedure of choice in many patients with preserved liver function. ${ }^{[5,6]}$

Minimally invasive management of HCC is increasing in frequency, including patients with underlying cirrhosis. ${ }^{[2,7-11]}$ There may be a number of benefits of laparoscopy over laparotomy for HCC, which have been widely reported. Potential benefits include decreased blood loss and need for blood transfusion, decreased complications (i.e. less postoperative ascites, wound infection), decreased length of stay, and reduced technical difficulty with subsequent surgery, including transplantation. ${ }^{[2,9,10,12,13]}$ Oncological principles can be maintained with laparoscopy and outcomes are comparable, if not better, with laparoscopy compared to open HCC resection. ${ }^{[13-17]}$ The benefits may derive from the pathophysiological changes that occur with laparoscopy compared to laparotomy, which may be accentuated in the presence of cirrhosis. These include less disruption of the abdominal wall, reduced immune response, and the tamponade effect of pneumoperitoneum.

Laparoscopic resection of HCC is technically challenging. It requires both laparoscopic skills and advanced liver surgical skills. The limited viewing angles, fulcrum effect of laparoscopic ports, instrument clash, reduced tactile feedback, and reduced operating dexterity pose significant challenges in complex surgery. Liver exploration and mobilization, hemorrhage control during parenchymal transection, the use of laparoscopic ultrasound, ensuring adequate oncological margins, and suturing can be more difficult with laparoscopy, especially in the presence of cirrhosis. ${ }^{[18]}$ The operative time is generally longer than open surgery. Skilled assistance is essential, and for long cases surgeon and assistant fatigue is common. The cirrhotic poses additional complexity with potentially altered vasculature in the abdominal wall, hilum and retroperitoneum, and a stiffened liver that resists laparoscopic handling. However, laparoscopic resection of HCC in both noncirrhotic and cirrhotic patients can provide good clinical outcomes, act as bridge-to-transplant and deliver acceptable survival rates. ${ }^{[19]}$

The worldwide experience in laparoscopic liver resection for HCC is increasing, although major resections are still limited to few centers. The current study describes our experience in Brisbane, Australia, with focus on perioperative outcomes.

\section{METHODS}

Data acquired from a prospectively collected laparoscopic liver surgery database from multiple centers in Brisbane, Australia, were examined and retrospectively reviewed. Ethics approval was obtained prior to the commencement of the study. Consecutive patients who underwent laparoscopic resection of HCC between January, 1999 and September, 2015 were selected. All patients underwent high quality preoperative imaging with contrast-enhanced computer tomography and magnetic resonance imaging. Selection for laparoscopic resection took into consideration tumor size and location, the degree of underlying liver disease and portal hypertension, and the patient's fitness and ability to tolerate a prolonged pneumoperitoneum. Patients with Child-Pugh B and $C$ cirrhosis were generally excluded. All patients were discussed and management was agreed upon at a multi-disciplinary team meeting.

Collected intraoperative data included details of the surgical procedure (minor vs. major; anatomic vs. nonanatomic), operation duration, blood loss and conversion to laparotomy. A wide range of clinicopathological factors were collected regarding underlying liver disease (METAVIR score), etiology, number and size of tumors, lymphatic or vascular invasion, tumor differentiation, presence of satellite nodules, and pathological margins. A microscopic margin of $\geq 1 \mathrm{~mm}$ was defined as $\mathrm{R} 0$.

Surgical technique had been described previously. ${ }^{[20,21]}$ In brief, pneumoperitoneum was established via an open access technique and maintained at $12-15 \mathrm{mmHg}$. Four to 6 working ports were used. The Pringle maneuver was used selectively. In selected patients with dome lesions, additional intercostal and transthoracic trocars were used. For major hepatectomies, inflow vascular structures were controlled with clips or vascular staplers and the hepatic veins were controlled extrahepatically. Parenchymal transection was performed using LigaSure (Covidien, Mansfield, MA, USA), harmonic 
Table 1: Baseline characteristics

\begin{tabular}{lc}
\hline Baseline characteristics & Median (range) or $\boldsymbol{n}(\%)$ \\
\hline Age, years & $58(44-81)$ \\
Female & 26 \\
$\alpha$-fetoprotein, $\mathrm{ng} / \mathrm{mL}$ & $8.5(1.7-59,000)^{*}$ \\
No cirrhosis & $18(35)$ \\
Cirrhosis & $34(65)$ \\
Child-Pugh class & \\
A & 33 \\
B & 1 \\
C & 0 \\
Known underlying liver disease & $37(71)$ \\
HBV & $2(4)$ \\
HCV & $23(46)$ \\
Alcohol & $3(6)$ \\
NASH & $5(10)$ \\
Unknown (with cirrhosis) & $4(8)$ \\
\hline
\end{tabular}

* $14.6 \%$ of patients had an $\alpha$-fetoprotein level $\geq 200 \mathrm{ng} / \mathrm{mL}$. HBV: hepatitis B virus; HCV: hepatitis C virus; NASH: non-alcoholic steatohepatitis

shears, or the $10 \mathrm{~mm}$ laparoscopic Cavitron Ultrasonic Surgical Aspirator (Integra Life sciences Corporation, NJ, USA), combined with use of locking clips (Hem-olok, Teleflex Medical, Durham, NC, USA) and staplers. Drains were reserved for patients deemed to be high risk for bile leak. Postoperatively, patients who underwent major resections ( $>3$ segments) were admitted to the intensive care unit (ICU). Patients with minor resections ( $<3$ segments) were admitted to the general surgical ward. Chemical and mechanical thromboprophylaxis were used routinely. Early mobilization and return to a normal diet was encouraged.

Postoperative parameters examined included duration of ICU and total hospital stay, postoperative morbidity (stratified according to the Clavien-Dindo system of classification), and 30-day and 90-day mortality. One-, 3and 5-year survival and disease-free survival status was recorded and actuarial survivals were estimated using the Kaplan-Meier method. Mid and long-term follow up included clinical, biological and radiological assessment 1-month post surgery and every subsequent 6-month. Survival follow-up was achieved through updated medical records and phone calls.

Statistical analyses were performed using R 3.2.0 ( $R$ Core Team, 2015). Categorical data were compared using Fisher's exact test; median values from continuous data were compared using the 2-sample rank test; $P$ values of $<0.05$ were considered statistically significant.

\section{RESULTS}

Fifty patients underwent a total of 52 operations. In total, 79 HCCs were resected. The annual frequency of laparoscopic resection of HCC in our centers gradually
Table 2: Operative characteristics

\begin{tabular}{|c|c|c|c|}
\hline $\begin{array}{l}\text { Operative } \\
\text { characteristics }\end{array}$ & Total & $\begin{array}{c}\text { Non- } \\
\text { cirrhotic }\end{array}$ & Cirrhotic \\
\hline $\begin{array}{l}\text { Laparoscopic liver } \\
\text { resection }\end{array}$ & 52 & 18 & 34 \\
\hline \multicolumn{4}{|l|}{$\begin{array}{l}\text { Major hepatectomy, } \\
n(\%)\end{array}$} \\
\hline Right hepatectomy & $4(8)$ & $4(22)$ & $0(0)$ \\
\hline Left hepatectomy & $1(2)$ & $1(6)$ & $0(0)$ \\
\hline $\begin{array}{l}\text { Extended right } \\
\text { hepatectomy }\end{array}$ & $2(4)$ & $0(0)$ & $2(6)$ \\
\hline $\begin{array}{l}\text { Left lateral } \\
\text { sectionectomy, } \\
n(\%)\end{array}$ & $11(21)$ & $4(22)$ & $6(18)$ \\
\hline $\begin{array}{l}\text { Segmentectomy, } \\
n(\%)\end{array}$ & $24(46)$ & 7 (39) & $17(50)$ \\
\hline $\begin{array}{l}\text { Subsegmental } \\
\text { resection, } n(\%)\end{array}$ & $10(19)$ & $2(11)$ & $9(26)$ \\
\hline $\begin{array}{l}\text { Posterosuperior } \\
\text { (segments } 1,4 a, 7 \text {, } \\
\text { 8) resections, } n(\%)\end{array}$ & $8(15)$ & $3(17)$ & $5(15)$ \\
\hline $\begin{array}{l}\text { Conversion to } \\
\text { laparotomy, } n(\%)\end{array}$ & $5(9)$ & $2(11)$ & $3(9)$ \\
\hline $\begin{array}{l}\text { Operating time, min, } \\
\text { median (range) }\end{array}$ & $120(75-300)$ & $117(75-240)$ & $120(90-300)$ \\
\hline $\begin{array}{l}\text { Blood loss, } \mathrm{mL} \text {, } \\
\text { median (range) }\end{array}$ & $300(20-1,600)$ & $150(20-600)$ & $350(30-1,600)$ \\
\hline
\end{tabular}

increased, from 7 patients during the early period (1999-2004), to 18 in the middle period (2005-2010), to 25 in the later period (2011-2015) [Figure 1]. The percentage of patients having cirrhosis also increased, from $57 \%$, to $67 \%$, to $72 \%$ respectively. Overall in this study, 34 patients $(65 \%)$ had cirrhosis (33 Child-Pugh A, 1 Child-Pugh B). Of the patients with cirrhosis, $56 \%$ had evidence of portal hypertension. The most common etiology of cirrhosis was hepatitis C $(65 \%)$ and nonalcoholic steatohepatitis (non-alcoholic steatohepatitis, $14 \%$ ). The baseline characteristics of the patients are summarized in Table 1.

Operative characteristics are summarized in Table 2. There were 7 (14\%) major hepatectomies, including 2 extended hemihepatectomies. Seventy-six percent of cirrhotic patients underwent a segmentectomy or subsegmentectomy, compared with $50 \%$ of noncirrhotic patients $(P=0.068)$.

There were 52 operations and of these, 51 were pure laparoscopic (including 2 involving the addition of intercostal or transthoracic trocars) and 1 was handassisted. There were 5 conversions (9\%), 3 of which (pure laparoscopic intent) were due an inability to progress as a result of difficult dissections secondary to intra-abdominal adhesions. One conversion occurred due to uncontrollable hemorrhage in a non-cirrhotic patient. The final conversion occurred in the handassisted case of a posterior dome lesion (segment 7/8). This patient had recognised positive margin due to the awkward angle and was opened for wider resection. 
Table 3: Postoperative and histopathological data

\begin{tabular}{lccc}
\hline $\begin{array}{l}\text { Postoperative and } \\
\text { histopathological data }\end{array}$ & All patients & Non-cirrhotic & Cirrhotic \\
\hline Length of hospital stay, days, & $5(1-72)$ & $5(3-13)$ & $5(1-72)$ \\
median (range) & & & $1(3)$ \\
Mortality, 90 -day, $n(\%)$ & $1(1.9)$ & $0(0)$ & $5(15)$ \\
Overall morbidity, $n(\%)$ & $7(13)$ & $2(11)$ & $2(6)$ \\
Infection & $3(6)$ & $1(6)$ & $3(9)$ \\
Ascites & $3(6)$ & $0(0)$ & $0(0)$ \\
Bile leak & $1(2)$ & $1(6)$ & 15 \\
Tumor margin, mm, median & 9 & 5 & $31(91)$ \\
Margin status, $n(\%)$ & & $17(94)$ & $3(9)$ \\
Ro & $48(92)$ & $1(6)$ & $28(5-220)$ \\
R1 & $4(8)$ & $40(20-150)$ & $1(1-5)$ \\
Tumor size, mm, median (range) & $33(5-220)$ & $1(1-2)$ & $15(44)$ \\
Number of tumors, median (range) & $1(1-5)$ & $2(11)$ & \\
Multifocality, $n$ (\%) & $17(33)$ & & $9(26)$ \\
Tumor differentiation, $n(\%)$ & & $6(33)$ & $23(67)$ \\
Well differentiated & $13(25)$ & $11(61)$ & $2(6)$ \\
Moderately differentiated & $36(70)$ & $1(6)$ & $9(26)$ \\
Poorly differentiated & $3(5)$ & $8(44)$ & $3(9)$ \\
Vascular invasion, $n$ (\%) & $17(33)$ & $1(6)$ & \\
Lymphatic invasion, $n(\%)$ & $4(9)$ & & \\
\hline
\end{tabular}

Subsequent cases involving dome lesions were preferentially performed with a combined transthoracic and transabdominal approach.

Median operative time was $120 \mathrm{~min}$ and median blood loss was $300 \mathrm{~mL}$. Patients with cirrhosis experienced more bleeding than those without (median $350 \mathrm{~mL}$ in cirrhotics vs. $150 \mathrm{~mL}$ in non-cirrhotics, $P=0.049$ ). The median length of stay was 5 days and was not different between the cirrhotic and non-cirrhotic groups.

Postoperative and pathological data are summarized in Table 3. There was 1 mortality, which occurred early in the series. The patient had Child-Pugh B cirrhosis and underwent a left lateral sectionectomy. Blood loss was $1,600 \mathrm{~mL}$ and this patient died due to decompensated liver failure. Overall 7 patients (13\%) developed a postoperative complication. Morbidity rates were not

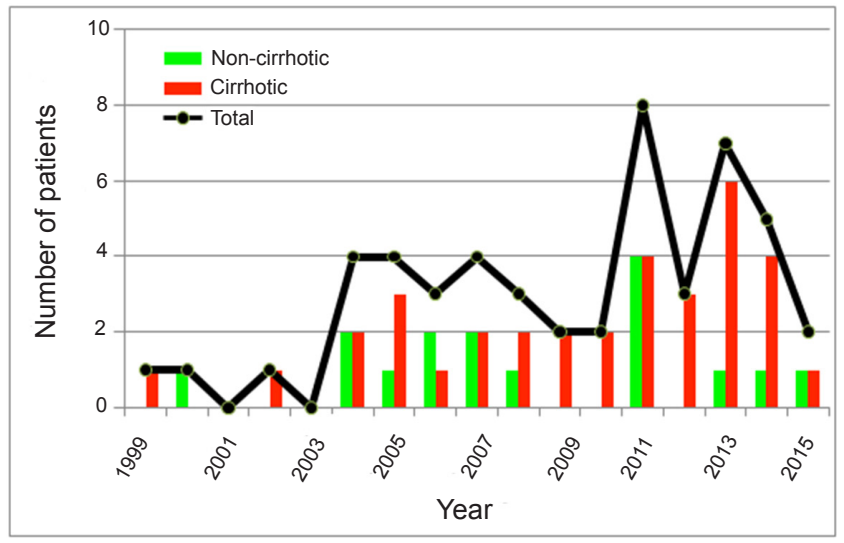

Figure 1: Annual frequency of laparoscopic resection of HCC. HCC: hepatocellular carcinoma different between patients with and without cirrhosis. Apart from the single post-operative mortality, all complications were Clavien-Dindo grade 1 or 2.

Multifocal HCC was far more prevalent in cirrhotics compared with non-cirrhotics (44\% vs. $11 \%, P=0.008)$. Multifocality was generally diagnosed incidentally on pathology of the resected specimen as patients with multifocal disease were excluded from resection. Microvascular invasion was present in 17 patients (33\%). Equivalent R0 resection rates were achieved for cirrhotics and non-cirrhotics (94\% vs. 91\%). Despite the higher rate of subsegmental resections, the median margin in cirrhotics was $15 \mathrm{~mm}$ compared with $5 \mathrm{~mm}$ in the non-cirrhotics $(P=0.067)$.

Median follow-up was 41 months. Median overall survival was 89 months. Overall survival for the entire cohort at 1,3 , and 5 years was $88 \%, 81 \%$, and $61 \%$, respectively [Figure 2]. The corresponding survival for non-cirrhosis patients was $93 \%, 77 \%$, and $67 \%$, and for patients with cirrhosis was $86 \%, 83 \%$, and $50 \%$. Disease-free survival at 5 years was $57 \%$ for all patients, $43 \%$ for non-cirrhosis, and $71 \%$ for patients with cirrhosis.

\section{DISCUSSION}

Laparoscopic liver resection is a technically demanding operation. The presence of cirrhosis increases the operative difficulty, and is considered a relative contraindication to laparoscopic resection in some centers. To our knowledge, there are no data suggesting poorer outcomes for patients who undergo 
laparoscopic compared to open liver resection in the setting of cirrhosis. In the current study, $65 \%$ of patients had cirrhosis (33 Child-Pugh A, 1 Child-Pugh B). There was a trend toward more segmental and subsegmental resections in cirrhotics compared to those without cirrhosis. This reflects the desire to spare parenchyma to reduce post-operative liver insufficiency, but this needs to be balanced against obtaining adequate margins, resecting the "oncological territory" of the tumor, and minimizing blood loss and bile leak. Recent publications have suggested that anatomic resection should be the norm due to the proclivity of HCC to invade the vasculature and metastasize within the liver. However, the heterogeneity with regards to the presence of cirrhosis may be a confounding factor. ${ }^{[22-24]}$

One patient with Child-Pugh B cirrhosis underwent a laparoscopic left lateral sectionectomy. This patient died within 30 postoperative days due to postoperative liver failure. This case occurred early in the series and as a result, Child-Pugh B status remains a relative contraindication to surgical resection in our center. However, other authors have demonstrated good short and long-term outcomes with reasonable safety in wellselected individuals. ${ }^{[25,26]}$

Compared to open resection, laparoscopy may have a number of benefits in the setting of cirrhosis. Laparoscopy allows for smaller incisions, which may lead to less disruption of the abdominal wall collateral circulation and cause less fluid shifts from exposure of the peritoneal cavity. In those series, 3 patients $(9 \%)$ with cirrhosis developed postoperative ascites. Postoperative ascites is common after liver resection, even when a relatively small amount of parenchyma is resected. Some studies have demonstrated less postoperative ascites after laparoscopic liver resection compared to laparotomy. ${ }^{[27-30]}$

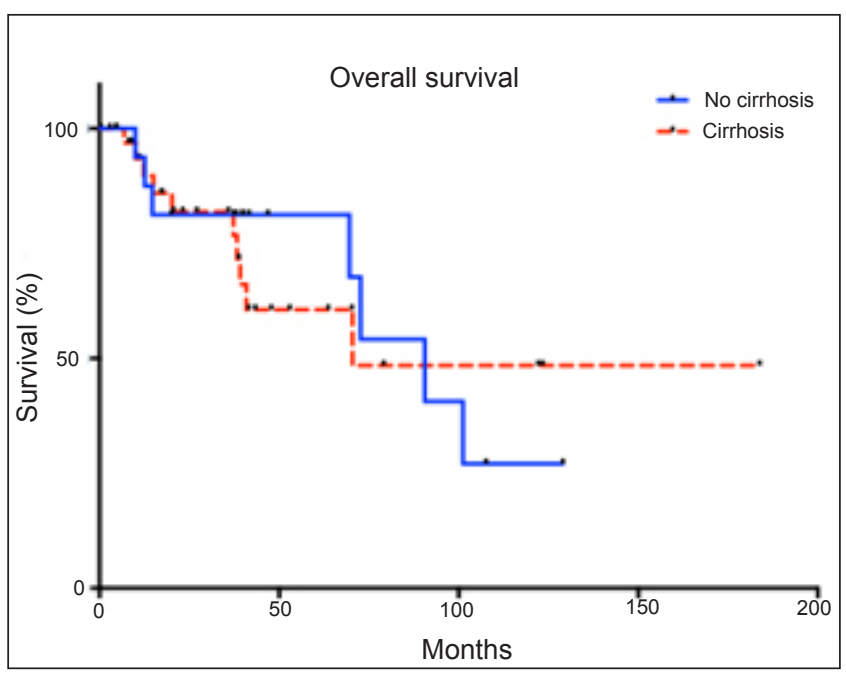

Figure 2: Kaplan-Meier survival analysis
Laparoscopy is also associated with less blood loss and subsequent need for blood transfusion compared to open surgery, ${ }^{[28,29,31]}$ possibly due to the tamponade effect of pneumoperitoneum on the exposed veins and intra-abdominal varices. To reduce blood loss, pneumoperitoneum can be transiently increased to pressures of $16-20 \mathrm{mmHg}$ during parenchymal transection. Despite concerns over the risk of $\mathrm{CO}_{2}$ embolism and respiratory compromise during highpneumoperitoneum, this was not a feature in our series. Laparoscopic ultrasound guidance assists in identifying major vascular structures during transection, but the sensitivity of intraoperative ultrasound in localizing small tumors is reduced in cirrhosis.

For parenchymal transection, we favor the use of the LigaSure which combines the sealing ability of bipolar coagulation forceps and recapitulates acrush-clamping technique. Laparoscopic staplers were used mainly for pedicle control and avoided for parenchymal transection due to their tendency to tear the cirrhotic liver.

Ensuring adequate margins is fundamental to the overall outcome of the surgery and subsequent patient prognosis. Whilst the benefits of digital palpation in open surgery may be overstated (especially in cirrhosis), laparoscopy eliminates this capability. ${ }^{[7,32]}$ We found the use of laparoscopic ultrasound essential in order to determine a precise transection line in relation to the tumor margin and locate important vascular structures. ${ }^{[32,33]}$

Straight resection planes are preferred whenever possible. This is relatively easy to achieve for a lateral sectionectomy or a major hepatectomy, dividing the liver along well defined scissura. However, in cases of laparoscopic non-anatomical subsegmentectomies, there is a significant risk of undermining the tumor leading to a positive margin. This is especially true for tumors with a wider circumference deep to the liver surface. Starting the dissection $2 \mathrm{~cm}$ wider, particularly on the side of the tumor nearest to the surgeon, helps achieve clearance of the deep margin. Angling the transection away from the tumor may reduce this risk and we frequently employ metal clips as ultrasound visible "markers" which are re-checked through the transection.

Laparoscopic management of liver tumors has been reported more commonly for lesions located within the anterolateral segments of the liver. Some centers consider posterosuperior lesions (segments $1,4 a, 7,8$ ), particularly dome lesions adjacent to the hepatic veins a contraindication for laparoscopic surgery. This is due to limited visualization, difficult angle of attack, and reduced capability to control the vena cava in the event 
of haemorrhage. ${ }^{[34-36]}$ Such difficulties can be partially overcome by performing a formal hepatectomy, but this is often not ideal as it may be important to preserve hepatic volume in the setting of cirrhosis. In our series, we had 8 dome lesions. During our early experience, we approached a segment 8 dome lesion with a handassisted technique. Adequate margins could not be obtained and the case required conversion. We have subsequently modified our technique to use intercostal and transthoracic trocars (ITT) for such lesions. We found that the ITT approach offered better visualization, access for resection and ability to control hemorrhage compared with the hand-assisted technique.

This study is limited by its retrospective nature. We showed that laparoscopic resection is feasible and safe, but without an open comparison group, the true perioperative benefits are unclear. The long-term recurrence and survival outcomes in our cohort need to be further investigated in order to further define the oncological equivalence of laparoscopic resection compared with open.

In conclusion, laparoscopic liver resection for hepatocellular carcinoma can be performed with acceptable morbidity and adequate surgical margins. The technical challenges of liver resection are often magnified with laparoscopy, particularly in patients with cirrhosis. However, such difficulties can be overcome with increasing experience. We believe that the benefits of a minimally invasive approach are also more pronounced in cirrhotics, due to the potential to reduce morbidity compared to an open approach. Future studies comparing laparoscopic to open resection with long-term follow-up should be performed to further define its role.

\section{Financial support and sponsorship None.}

\section{Conflicts of interest}

There are no conflicts of interest.

\section{Patient consent}

Necessary consent was obtained.

\section{Ethics approval}

Approved by an institutional board at Royal Brisbane Hospital.

\section{REFERENCES}

1. El-Serag HB, Rudolph KL. Hepatocellular carcinoma: epidemiology and molecular carcinogenesis. Gastroenterology 2007;132:2557-76.

2. Lai EC, Tang CN, Ha JP, Li MK. Laparoscopic liver resection for hepatocellular carcinoma: ten-year experience in a single center. Arch
Surg 2009;144:143-7; discussion 148.

3. Venook AP, Papandreou C, Furuse J, de Guevara LL. The incidence and epidemiology of hepatocellular carcinoma: a global and regional perspective. Oncologist 2010;15 Suppl 4:5-13.

4. Altekruse SF, Henley SJ, Cucinelli JE, McGlynn KA. Changing hepatocellular carcinoma incidence and liver cancer mortality rates in the United States. Am J Gastroenterol 2014;109:542-53.

5. Lau WY. Management of hepatocellular carcinoma. $J$ R Coll Surg Edinb 2002;47:389-99.

6. Lai EC, Lau WY. The continuing challenge of hepatic cancer in Asia Surgeon 2005;3:210-5.

7. Gigot JF, Glineur D, Santiago Azagra J, Goergen M, Ceuterick M, Morino M, Etienne J, Marescaux J, Mutter D, van Krunckelsven L, Descottes B, Valleix D, Lachachi F, Bertrand C, Mansvelt B, Hubens G, Saey JP, Schockmel R; Hepatobiliary, Pancreatic Section of the Royal Belgian Society of Surgery; the Belgian Group for Endoscopic Surgery. Laparoscopic liver resection for malignant liver tumors: preliminary results of a multicenter European study. Ann Surg 2002;236:90-7.

8. Tang CN, Li MK. Laparoscopic-assisted liver resection.J Hepatobiliary Pancreat Surg 2002;9:105-10

9. Gagner M, Rogula T, Selzer D. Laparoscopic liver resection: benefits and controversies. Surg Clin North Am 2004;84:451-62.

10. Cherqui D, Laurent A, Tayar C, Chang S, Van Nhieu JT, Loriau J, Karou M, Duvoux C, Dhumeaux D, Fagniez PL. Laparoscopic liver resection for peripheral hepatocellular carcinoma in patients with chronic liver disease: midterm results and perspectives. Ann Surg 2006;243:499-506.

11. Tang CN, Tsui KK, Ha JP, Yang GP, Li MK. A single-centre experience of 40 laparoscopic liver resections. Hong Kong Med J 2006;12:419-25.

12. Dagher I, Lainas P, Carloni A, Caillard C, Champault A, Smadja C, Franco D. Laparoscopic liver resection for hepatocellular carcinoma. Surg Endosc 2008;22:372-8.

13. Li N, Wu YR, Wu B, Lu MQ. Surgical and oncologic outcomes following laparoscopic versus open liver resection for hepatocellular carcinoma: a meta-analysis. Hepatol Res 2012;42:51-9.

14. Shimada M, Hashizume M, Maehara S, Tsujita E, Rikimaru T, Yamashita Y, Tanaka S, Adachi E, Sugimachi K. Laparoscopic hepatectomy for hepatocellular carcinoma. Surg Endosc 2001;15:541-4.

15. Belli G, Fantini C, D’Agostino A, Belli A, Langella S. Laparoscopic hepatic resection for completely exophytic hepatocellular carcinoma on cirrhosis. J Hepatobiliary Pancreat Surg 2005;12:488-93.

16. Kaneko H, Takagi S, Otsuka Y, Tsuchiya M, Tamura A, Katagiri T, Maeda T, Shiba T. Laparoscopic liver resection of hepatocellular carcinoma. Am J Surg 2005;189:190-4.

17. Belli G, Fantini C, Belli A, Limongelli P. Laparoscopic liver resection for hepatocellular carcinoma in cirrhosis: long-term outcomes. Dig Surg 2011;28:134-40.

18. Buell JF, Cherqui D, Geller DA, O'Rourke N, Iannitti D, Dagher I, Koffron AJ, Thomas M, Gayet B, Han HS, Wakabayashi G, Belli G, Kaneko H, Ker CG, Scatton O, Laurent A, Abdalla EK, Chaudhury P, Dutson E, Gamblin C, D'Angelica M, Nagorney D, Testa G, Labow D, Manas D, Poon RT, Nelson H, Martin R, Clary B, Pinson WC, Martinie J, Vauthey JN, Goldstein R, Roayaie S, Barlet D, Espat J, Abecassis M, Rees M, Fong Y, McMasters KM, Broelsch C, Busuttil R, Belghiti J, Strasberg S, Chari RS; World Consensus Conference on Laparoscopic Surgery. The international position on laparoscopic liver surgery: the Louisville Statement, 2008. Ann Surg 2009;250:825-30.

19. Nguyen KT, Gamblin TC, Geller DA. World review of laparoscopic liver resection - 2,804 patients. Ann Surg 2009;250: 831-41.

20. O'Rourke N, Fielding G. Laparoscopic right hepatectomy: surgical technique. J Gastrointest Surg 2004;8:213-6.

21. Chiow AK, Lewin J, Manoharan B, Cavallucci D, Bryant R, O'Rourke $\mathrm{N}$. Intercostal and transthoracic trocars enable easier laparoscopic resection of dome liver lesions. HPB (Oxford) 2015;17:299-303. 
22. Cucchetti A, Cescon M, Ercolani G, Bigonzi E, Torzilli G, Pinna AD. A comprehensive meta-regression analysis on outcome of anatomic resection versus nonanatomic resection for hepatocellular carcinoma. Ann Surg Oncol 2012;19:3697-705.

23. Eguchi S, Kanematsu T, Arii S, Okazaki M, Okita K, Omata M, Ikai I, Kudo M, Kojiro M, Makuuchi M, Monden M, Matsuyama Y, Nakanuma Y, Takayasu K; Liver Cancer Study Group of Japan. Comparison of the outcomes between an anatomical subsegmentectomy and a nonanatomical minor hepatectomy for single hepatocellular carcinomas based on a Japanese nationwide survey. Surgery 2008;143:469-75.

24. Regimbeau JM, Kianmanesh R, Farges O, Dondero F, Sauvanet A, Belghiti J. Extent of liver resection influences the outcome in patients with cirrhosis and small hepatocellular carcinoma. Surgery 2002;131:311-7.

25. Guglielmi A, Ruzzenente A, Conci S, Valdegamberi A, Vitali M, Bertuzzo F, De Angelis M, Mantovani G, Iacono C. Hepatocellular carcinoma: surgical perspectives beyond the barcelona clinic liver cancer recommendations. World J Gastroenterol 2014;20:7525-33.

26. Garancini M, Pinotti E, Nespoli S, Romano F, Gianotti L, Giardini V. Hepatic resection beyond barcelona clinic liver cancer indication: when and how. World J Hepatol 2016;8:513-9.

27. Belli G, Fantini C, D’Agostino A, Cioffi L, Langella S, Russolillo N, Belli A. Laparoscopic versus open liver resection for hepatocellular carcinoma in patients with histologically proven cirrhosis: short- and middle-term results. Surg Endosc 2007;21:2004-11.

28. Zhou YM, Shao WY, Zhao YF, Xu DH, Li B. Meta-analysis of laparoscopic versus open resection for hepatocellular carcinoma. Dig Dis Sci 2011;56:1937-43.
29. Xiong JJ, Altaf K, Javed MA, Huang W, Mukherjee R, Mai G, Sutton R, Liu XB, Hu WM. Meta-analysis of laparoscopic $v$ s. open liver resection for hepatocellular carcinoma. World J Gastroenterol 2012;18:6657-68.

30. Memeo R, de'Angelis N, Compagnon P, Salloum C, Cherqui D Laurent A, Azoulay D. Laparoscopic vs. open liver resection for hepatocellular carcinoma of cirrhotic liver: a case-control study. World J Surg 2014;38:2919-26.

31. Simillis C, Constantinides VA, Tekkis PP, Darzi A, Lovegrove R, Jiao $\mathrm{L}$, Antoniou A. Laparoscopic versus open hepatic resections for benign and malignant neoplasms--a meta-analysis. Surgery 2007;141:203-11.

32. Rahusen FD, Cuesta MA, Borgstein PJ, Bleichrodt RP, Barkhof F, Doesburg T, Meijer S. Selection of patients for resection of colorectal metastases to the liver using diagnostic laparoscopy and laparoscopic ultrasonography. Ann Surg 1999;230:31-7.

33. John TG, Greig JD, Crosbie JL, Miles WF, Garden OJ. Superior staging of liver tumors with laparoscopy and laparoscopic ultrasound. Ann Surg 1994;220:711-9.

34. Cherqui D, Husson E, Hammoud R, Malassagne B, Stephan F, Bensaid S, Rotman N, Fagniez PL. Laparoscopic liver resections: a feasibility study in 30 patients. Ann Surg 2000;232:753-62.

35. Laurent A, Cherqui D, Lesurtel M, Brunetti F, Tayar C, Fagniez PL. Laparoscopic liver resection for subcapsular hepatocellular carcinoma complicating chronic liver disease. Arch Surg 2003;138:763-9; discussion 769.

36. Dulucq JL, Wintringer P, Stabilini C, Berticelli J, Mahajna A Laparoscopic liver resections: a single center experience. Surg Endosc 2005;19:886-91. 